\title{
Correlation between Acoustic Emission activity and asperity contact during meshing of spur gears under partial elastohydrodynamic lubrication
}

\author{
C. K. Tan, D. Mba \\ School of Engineering, Cranfield University, Bedfordshire. MK43 0AL, United Kingdom \\ Tel: +44 1234 754681, E:-mail d.mba@cranfield.ac.uk
}

\begin{abstract}
This paper presents results of an experimental programme that suggested a correlation between levels of Acoustic Emission (AE) activity and the frictional resistance of contacting asperities of spur gears under partial elastohydrodynamic lubrication.
\end{abstract}

\section{INTRODUCTION}

An experimental investigation undertaken by Tan et al [1] to explore the application of Acoustic Emission (AE) in gearbox condition monitoring revealed a lack of understanding on the source mechanism of AE during the gear mesh, and, the gearbox operating parameters that influenced AE activity. Tan observed AE transient bursts superimposed on continuous type AE's. A continuous type AE refers to a waveform where transient bursts are not discernible [2]. Tan attributed the rate of occurrence of the transient AE burs to gear mesh frequency. Furthermore, it was also observed that the 
gearbox oil temperature influenced AE levels for fixed speed and load conditions. To date no investigation has directly addressed the source of AE during the gear mesh.

Boness et al [3] stated that the sliding of mating surfaces was a continuous process and as such the $\mathrm{AE}$ signature from such a process would be predominantly continuous with superimposed burst emissions due to rapid high-amplitude events, for instance, a single asperity fracture. The investigation reported by Boness at al [3] involved the measurement of AE for dry and lubricated contacts under pure sliding conditions. It was reported that with a full elastohydrodynamic film between highly polished surfaces no AE r.m.s activity above the electronic noise of the acquisition system, inferring that asperity contact was the prime source for the generation of AE activity. It was also noted that increasing the film thickness resulted in a decrease of AE r.m.s levels. Dornfeld's [4] investigation supports the findings of Boness though both cases detailed above were for pure sliding conditions. During the gear mesh a combination of sliding and rolling occur and it is the aim of this investigation to identify the sources of AE during the mesh. To accomplish this, the influence of speed, load and lubricating condition on AE activity were investigated under near isothermal conditions. The reason for undertaking tests in conditions of constant temperature was because Tan [1] had observed changing AE levels with variation in temperature even though the speed and load conditions were constant. Therefore the constant temperature test were undertaken to eliminate the influence of oil temperature during tests. 


\section{EXPERIMENTAL SET-UP AND ACQUISITION SYSTEM}

The test-rig employed consisted of two identical oil-bath lubricated gearboxes connected in back-to-back arrangement. The gear set employed were made of 045M15 steel with 49 and 65 teeth. Each gear had no heat treatment, a module of $3 \mathrm{~mm}$, a pressure angle of $20^{\circ}$,

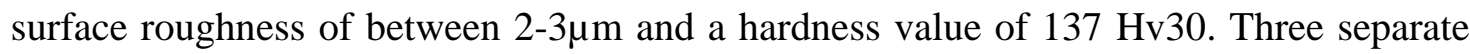
motors were employed offering rotational speeds of 745, 1460 and 2800rpm. The lubricant used to minimise pitting and wear was an EP SAE 80W-90, GL-4 API multigrade gearbox oil. The AE sensor used for this experiment was a broadband type sensor with a relatively flat response in the region between $100 \mathrm{KHz}$ to $1 \mathrm{MHz}$ (Model: WD, 'Physical Acoustics Corporation'). The sensor was placed on pinion (49 teeth) with the cable feed into the shaft and connected to a slip ring. This arrangement allowed the AE sensor to be placed as close as possible to the gear teeth. The output signal from the AE sensors was pre-amplified at $40 \mathrm{~dB}$. The AE waveform was acquired at a sampling rate of $10 \mathrm{MHz}$, whilst continuous Acoustic Emission r.m.s values were calculated in real time by the analogue-to-digital converter (ADC) controlling software; time interval 10ms at an acquisition rate of $10 \mathrm{~ms}$ as well. Prior to the ADC anti-aliasing filters were employed. Due to the large amounts of data collected over the test period the AE r.m.s values presented were averaged every five seconds. 


\section{EXPERIMENTAL PROCEDURE}

In identifying the sources of AE during meshing of gears the influence of operational variables such as speed and load were investigated. All film thickness calculations for the varying test conditions are detailed in appendix A.

\subsection{The effect of load on AE levels}

The gearbox was run at $745 \mathrm{rpm}$ with a load of $220 \mathrm{Nm}$ for 5 hours at which time the oil temperature reached equilibrium at $40.3^{0} \mathrm{C}$. The gearbox was brought to a stop and the load was re-adjusted to $73 \mathrm{Nm}$. The gearbox was re-started and run for 15 minutes whilst continuous AE r.m.s data was recorded. The gearbox was again brought to a stop and adjusted to the next load of $147 \mathrm{Nm}$. The rig was run for a further 15 minutes. Following the third load condition $(220 \mathrm{Nm})$ the gearbox load was reduced to $147 \mathrm{Nm}$ and finally to 73Nm. The prime purpose was to ensure consistency during testing. Each test was undertaken twice. The time taken to set the new torque level was approximately three minutes. In these tests, the average oil temperature was $40.1^{0} \mathrm{C}$ with a maximum temperature difference of $\pm 0.55^{\circ} \mathrm{C}$. The same procedure was repeated at a speed of 1460rpm. The results of these tests are presented in figure 1. It was evident that there was relatively little change in observed AE r.m.s values for varying torque conditions under isothermal conditions. This is the first known report detailing this finding. 

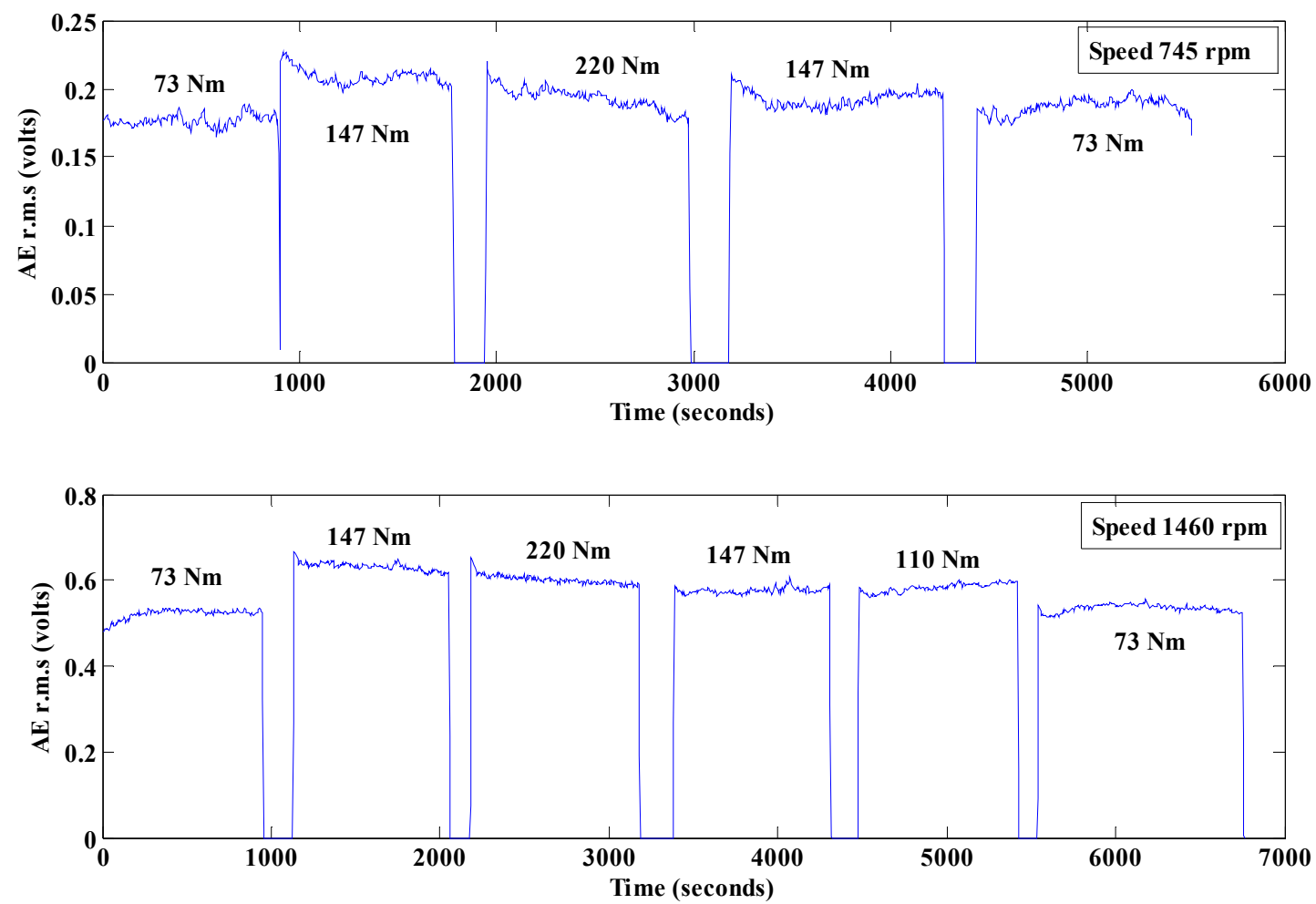

Figure 1 AE r.m.s levels at 745rpm and 1460rpm for varying load conditions under near isothermal conditions

\subsection{The effect of speed on AE levels}

The gearbox was run at $1460 \mathrm{rpm}$ with a load of $220 \mathrm{Nm}$ for 5 hours at which time the oil temperature stabilised at $50.0^{\circ} \mathrm{C}$. The gearbox was brought to a stop and a lower speed motor of 745 rpm was installed. The gearbox was re-started and run for 15 minutes whilst continuous AE r.m.s data was recorded. This procedure was repeated for another two load conditions; 147 and 73Nm, and speed conditions; 1460 and 2800rpm. A maximum torque level of $73 \mathrm{Nm}$ was applied for the test speed of 2800rpm due to the breakage/loss 
of $\mathrm{AE}$ signals as a result of high vibration levels saturating the AE high-pass filters on the pre-amplifier. The time taken to strip replace the motor was approximately four minutes and during this period the acquisition system was paused. The average oil temperatures were at $49.6^{0} \mathrm{C}, 47.7^{\circ} \mathrm{C}$ and $45.6^{\circ} \mathrm{C}$ for the respective load condition 220,147 and $73 \mathrm{Nm}$. A maximum temperature difference of $\pm 1.0^{0} \mathrm{C}$ was recorded for each test condition. Results of the test at the three load conditions investigated are illustrated in figure 2 . It was observed that changes in speed under fixed torque conditions had relatively significant changes in measured AE r.m.s values under isothermal conditions.
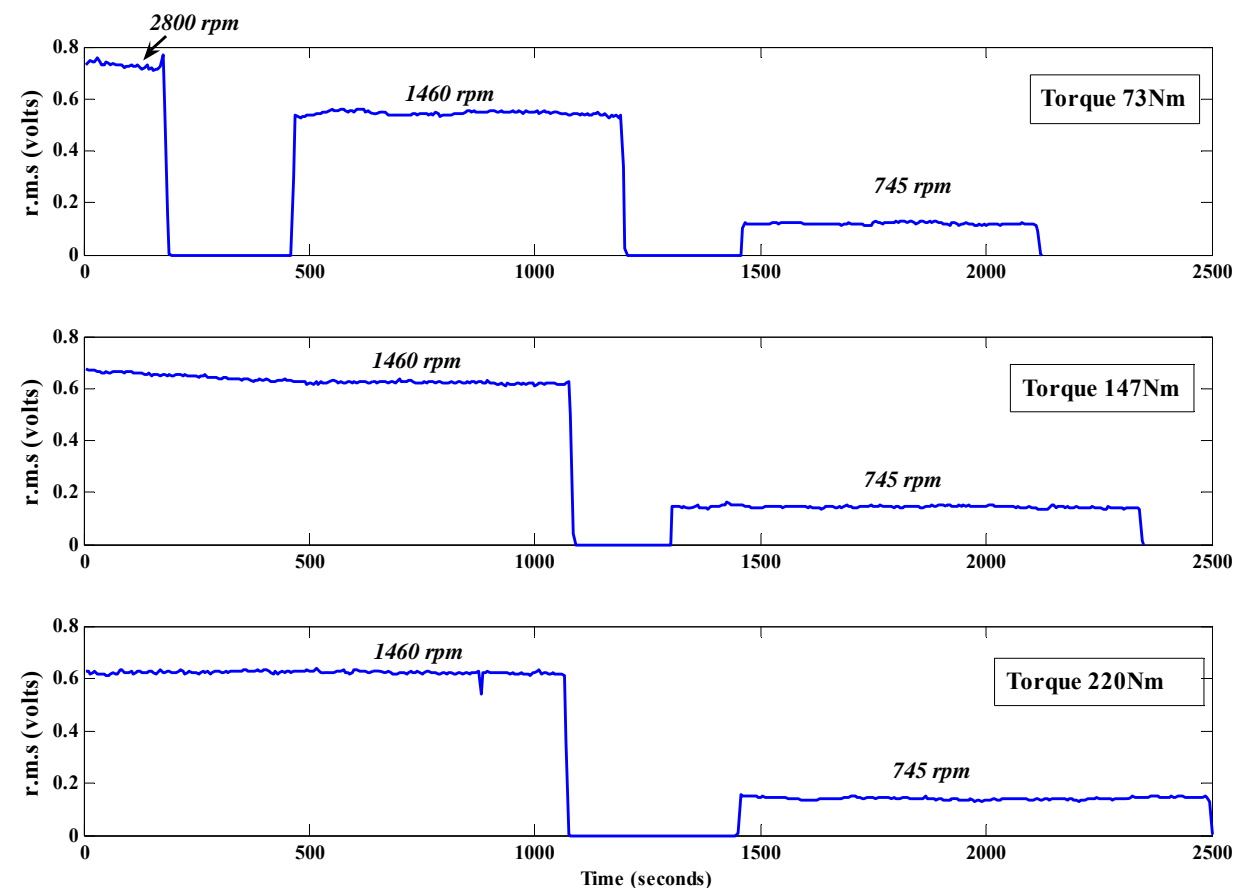

Figure 2 AE r.m.s levels for 745, 1460 and 2800rpm at 73, 147 and 220Nm 


\section{RESULTS, OBSERVATIONS AND DISCUSSIONS}

Under all test conditions observations of the $\mathrm{AE}$ waveform revealed transient bursts superimposed on continuous type AE signatures, see figure 3. The burst type emission occurred at periods corresponding to the gear mesh frequency. Due to this obvious periodicity it was concluded that the rolling portion of the gear mesh was largely responsible for generating $\mathrm{AE}$ transient bursts, as seen in figure 3.

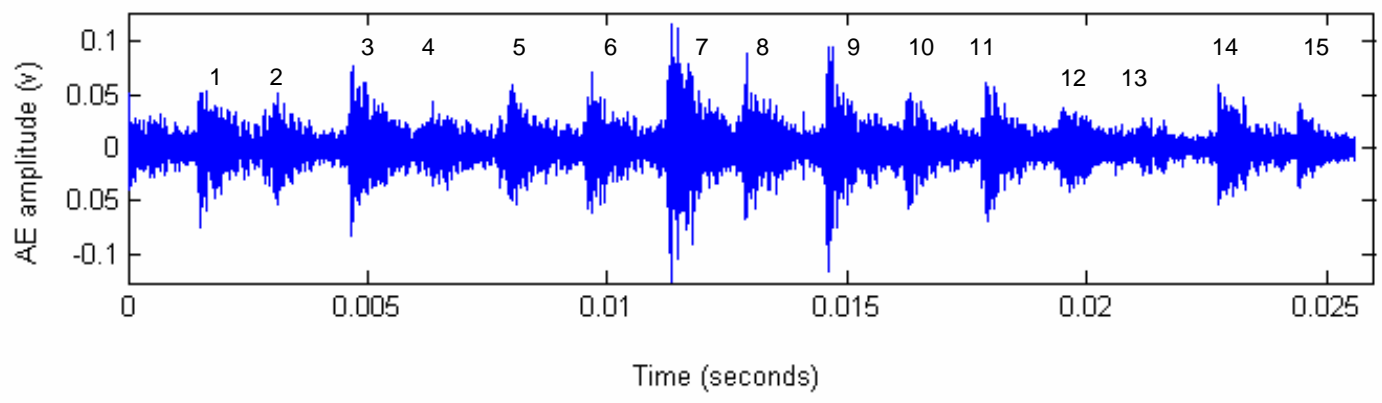

Figure 3 AE transient bursts representing fifteen meshing gear pairs

After the entire test conditions described, an inspection on the gear surface condition was performed and no visible damage such as scoring or pitting was present. This provided strong evidence that the transient $\mathrm{AE}$ bursts were not generated by either wear of gear teeth surface or tip/root interference during gear operation.

Prior to making comparisons the average values of AE r.m.s associated with each test condition were obtained by averaging all data points for each individual test condition. Percentage changes relative to the mean AE r.m.s value for both the load and speed conditions were investigated; see tables I and II. Doubling the rotational speed from 
$745 \mathrm{rpm}$ to $1460 \mathrm{rpm}$ at torque conditions of 220,147 and $73 \mathrm{Nm}$ resulted in an increase in AE r.m.s value of 329\%, 336\% and 350\% respectively; whereas doubling the load from $73 \mathrm{Nm}$ to $147 \mathrm{Nm}$ at $745 \mathrm{rpm}$ and $1460 \mathrm{rpm}$ resulted in an increase in $\mathrm{AE}$ r.m.s of $10 \%$ and $14 \%$ respectively. In addition, tripling the torque from $73 \mathrm{Nm}$ to $220 \mathrm{Nm}$ at $745 \mathrm{rpm}$ and 1460rpm resulted in a comparable increase as observed when the loads were doubled, 6\% and $14 \%$ respectively. It was interesting to note that when the speed was doubled from 1460 to 2800rpm the increase in AE r.m.s was 34\%. The reasons for the reduced percentage increase, in comparison to changes between 745 and 1460rpm, will be detailed later in this paper. The variation in AE r.m.s for each individual test condition was observed by calculating the standard deviation and coefficient of variation (CV); see tables I and II. In addition, the maximum and minimum r.m.s values for each test condition are also detailed. A high CV indicates high variability of the AE r.m.s values. As the $\mathrm{CV}$ values calculated ranged from $1 \%$ to $5 \%$ it was concluded that the variation in AE r.m.s for each test condition was within the range to be expected for experimental analysis.

Table I Variation in AE r.m.s under fixed load conditions

\begin{tabular}{clccccc} 
Load & & Max & Min & Mean & Std & CV (\%) \\
\hline $\mathbf{7 3 ~} \mathbf{~ N m}$ & & & & & & \\
& 2800 $\mathbf{~ p m}$ & 0.85 & 0.651 & 0.731 & 0.021 & 2.91 \\
& $\mathbf{1 4 6 0} \mathbf{~ p m}$ & 0.584 & 0.512 & 0.545 & 0.01 & 1.83 \\
& $\mathbf{7 4 5} \mathbf{~ p m}$ & 0.15 & 0.1 & 0.121 & 0.007 & 5.48 \\
$\mathbf{1 4 7} \mathbf{~ N m}$ & & & & & & \\
& $\mathbf{1 4 6 0} \mathbf{~ r p m}$ & 0.69 & 0.597 & 0.633 & 0.017 & 2.65 \\
& $\mathbf{7 4 5} \mathbf{~ r p m}$ & 0.172 & 0.125 & 0.145 & 0.007 & 4.63 \\
$\mathbf{2 2 0 ~ N m}$ & & & & & & \\
& $\mathbf{1 4 6 0} \mathbf{~ p m}$ & 0.65 & 0.597 & 0.623 & 0.008 & 1.27 \\
& $\mathbf{7 4 5} \mathbf{~ p m}$ & 0.164 & 0.12 & 0.141 & 0.007 & 4.82
\end{tabular}


Table II Variation in AE r.m.s under fixed speed conditions

\begin{tabular}{llccccc} 
Speed & & Max & Min & Mean & Std & CV (\%) \\
\hline $\mathbf{7 4 5} \mathbf{~ r p m}$ & & & & & & \\
& $\mathbf{7 3 ~ N m}$ & 0.2036 & 0.1566 & 0.1772 & 0.0068 & 3.84 \\
& $\mathbf{1 4 7 N m}$ & 0.2374 & 0.186 & 0.2093 & 0.0079 & 3.77 \\
& $\mathbf{2 2 0 N m}$ & 0.23 & 0.1652 & 0.1937 & 0.0096 & 4.96 \\
& $\mathbf{1 4 7 N m}$ & 0.2194 & 0.1668 & 0.1931 & 0.0079 & 4.09 \\
& $\mathbf{7 3 ~ N m}$ & 0.2174 & 0.1582 & 0.1877 & 0.0081 & 4.32 \\
$\mathbf{1 4 6 0} \mathbf{~ r p m}$ & & & & & & \\
& $\mathbf{7 3 ~ N m}$ & 0.5536 & 0.4662 & 0.5226 & 0.0136 & 2.6 \\
& $\mathbf{1 4 7 N m}$ & 0.6856 & 0.5804 & 0.6331 & 0.0114 & 1.8 \\
& $\mathbf{2 2 0 N m}$ & 0.6644 & 0.5694 & 0.6026 & 0.0121 & 2.01 \\
& $\mathbf{1 4 7 N m}$ & 0.619 & 0.55 & 0.5767 & 0.0093 & 1.61 \\
& $\mathbf{1 1 0 N m}$ & 0.614 & 0.5444 & 0.584 & 0.0116 & 1.99 \\
& $\mathbf{7 3 ~} \mathbf{N m}$ & 0.57 & 0.5012 & 0.5356 & 0.0106 & 1.98
\end{tabular}

From these results it is apparent that load has a relatively small influence on AE levels under conditions of constant temperature. Figure 1 depicts this observation clearly; however, speed had a significant influence on AE levels, see figure 2. This finding has a direct correlation with film thickness levels under elastohydrodynamic lubricating conditions, where the influence of load on film thickness is negligible [5] in comparison to speed. The relatively small variation in AE r.m.s levels with load is attributed to the small variation in temperature during testing and the small influence of the load on film thickness.

As has already been discussed both load and speed influence the AE levels during sliding $[3,4]$. An increase in rotational speed, and hence sliding speed of the meshing gears, will result in an increase in $\mathrm{AE}$ levels on the basis that asperity contact exists during the 
sliding portion of the mesh cycle. An increase in speed will result an increase in strain rate of the asperities in contact and this will generate higher AE levels [6]. On the contrary, an increase in film thickness at the pitch line (rolling portion of the mesh cycle), due to an increase in speed will cause a reduction in $\mathrm{AE}$ levels, if the source of the $\mathrm{AE}$ burst emission is from asperity contact at the rolling point. A thicker film will result in less asperity contact, hence less AE activity. Observations from this investigation shows that both sliding and rolling contribute to the overall AE levels observed. It is postulated that the main source of AE is due to asperity contact under sliding and rolling. This remark is based on the theoretical prediction of film thickness as experimental measurements of film thickness were not undertaken during these tests

AE r.m.s levels were seen to rise over 300\% with increasing speed, 745 to $1460 \mathrm{rpm}$. The reason for increased $\mathrm{AE}$ levels with speed is attributed to the higher strain rate the asperities experience at higher speeds. However, at a rotational speed of 2800rpm the increase in AE levels were 10-fold less than observed for the speed increase from 745 to 1460rpm. This would suggest that at this speed the influence of film thickness had caused a reduction in the rate of increase in AE levels. It will be expected that a further increases in speed will actually cause a gradual reduction in AE levels as a full elastohydrodynamic film is approached. The authors argue, as observed in this investigation, that an increase in speed from 745rpm to 1460rpm, with a corresponding increase in specific film thickness (approximately 0.3 and 0.4 respectively, appendix table A) was significant in its influence on AE levels in comparison to the specific film thickness of 0.6 at 2800rpm. 
The authors believe that there are four processes influencing the generation of AE during the gear mesh; high strain rates with increasing speeds, increasing film thickness in separating asperities with increasing speed, the level/amount of sliding and rolling contact during the mesh. The influence of the latter two can be related to their frictional resistance. The relationship between sliding and rolling friction has been investigated [5]. It was shown that whilst the rolling friction traction is independent of load the sliding friction traction is influenced by the lubricant viscosity and load. Furthermore, it was shown that increasing rolling speed resulted in a reduction of friction traction for a fixed load and lubricant viscosity. Following observations presented in this paper of relatively constant AE r.m.s values at a fixed speed and temperature irrespective of load, and the reduction of relatively increasing $\mathrm{AE}$ levels with increasing speed, some resemblance to the phenomena of rolling and sliding friction under elastohydrodynamic lubrication is evident. The relationship between AE and sliding friction has been reported $[4,6$ 7] where an increase in AE levels with increased sliding speed and load was noted. In summary the authors believe that the rotational speed and specific film thickness influence the AE levels from sliding and rolling.

\section{CONCLUSIONS}

In summary the following was observed:

I. Load had minimal influence on levels of AE r.m.s under isothermal conditions

II. Speed had a significant influence on AE r.m.s levels under isothermal conditions

III. Sliding contact was responsible for generating continuous type AE waveform

IV. Rolling contact generated AE transients at the gear mesh frequency 
$\mathrm{V}$. The proportion of sliding and rolling contact to the generation of AE is dependent on the rotational speed of the gears and specific film thickness. There is a strong dependence of the sliding and rolling regime to the overall levels of AE.

It is proposed that the AE technique offers the potential for assessing the level of asperity contact under a variety of operational and material conditions (speed, surface roughness, lubricant temperature, etc) in real time. Further investigations will be the subject of future publications.

\section{REFERENCES}

1. Chee Keong Tan and David Mba, Identification of the Acoustic Emission source during a comparative study on diagnosis of a spur gearbox, Tribology International, 38, 5 (2005), 469.

2. Non-destructive testing handbook, Volume 5 - Acoustic Emissions. (Published by the American Society of Non-destructive testing) ISBN 0-931403-02-2.

3. Boness, R. J., McBride S.L., and Sobczyk, M., Wear studies using Acoustic Emission techniques. Tribology International, 23, 5 (1990), 291.

4. Dornfeld, D. and Handy, C., Slip detection using acoustic emission signal analysis. IEEE International Conference on Robotics and Automation. 4 (1987).

5. Dowson, D. and Higginson, G.R. Elasto-hydrodynamic Lubrication. $1^{\text {st }}$ ed. (Oxford: Pergamon Press, 1977) ISBN 0080213022. 
6. Sarychev, G. A, and Shchavelin, V. M., Acoustic emission method for research and control of friction pairs. Tribology International. 24, 1 (1991), 11.

7. Jiaa, C. L. and Dornfeld, D. A., Experimental studies of sliding friction and wear via acoustic emission signal analysis. Wear. 139, (1990), 403.

\section{APPENDIX A}

Table A Film thickness calculations [5]

\begin{tabular}{|c|c|c|c|c|}
\hline $73 \mathrm{Nm}$ & $\begin{array}{c}\text { Temperature } \\
\left({ }^{\circ} \mathrm{C}\right)\end{array}$ & $\begin{array}{c}\text { Kinematic } \\
\text { viscosity } \\
\left(\mathrm{mm}^{2} / \mathbf{s}\right)\end{array}$ & $\begin{array}{c}\text { Oil film } \\
\text { thickness }(\mu \mathrm{m})\end{array}$ & $\begin{array}{c}\text { Specific film } \\
\text { thickness }\end{array}$ \\
\hline 745rpm & 45.4 & 99.744 & 0.768 & 0.310 \\
\hline 1460rpm & 45.8 & 97.776 & 1.064 & 0.430 \\
\hline 2800rpm & 45.3 & 100.244 & 1.492 & 0.603 \\
\hline $147 \mathrm{Nm}$ & $\begin{array}{c}\text { Temperature } \\
\left({ }^{\circ} \mathrm{C}\right)\end{array}$ & $\begin{array}{c}\text { Kinematic } \\
\text { viscosity } \\
\left(\mathrm{mm}^{2} / \mathbf{s}\right)\end{array}$ & $\begin{array}{c}\text { Oil film } \\
\text { thickness }(\mu \mathrm{m})\end{array}$ & $\begin{array}{c}\text { Specific film } \\
\text { thickness }\end{array}$ \\
\hline 745rpm & 47.3 & 90.821 & 0.732 & 0.296 \\
\hline 1460rpm & 48.0 & 87.791 & 1.008 & 0.407 \\
\hline $220 \mathrm{Nm}$ & $\begin{array}{c}\text { Temperature } \\
\left({ }^{\circ} \mathrm{C}\right)\end{array}$ & $\begin{array}{c}\text { Kinematic } \\
\text { viscosity } \\
\left(\mathrm{mm}^{2} / \mathrm{s}\right)\end{array}$ & $\begin{array}{c}\text { Oil film } \\
\text { thickness }(\mu \mathrm{m})\end{array}$ & $\begin{array}{c}\text { Specific film } \\
\text { thickness }\end{array}$ \\
\hline 745rpm & 48.9 & 84.083 & 0.705 & 0.285 \\
\hline 1460rpm & 50.3 & 78.704 & 0.954 & 0.386 \\
\hline
\end{tabular}

